\title{
IGCM4: a fast, parallel and flexible intermediate climate model
}

\author{
M. Joshi ${ }^{1,2}$, M. Stringer ${ }^{3}$, K. van der Wiel ${ }^{1,2}$, A. O'Callaghan ${ }^{1,2}$, and S. Fueglistaler ${ }^{4}$ \\ ${ }^{1}$ Centre for Ocean and Atmospheric Sciences, University of East Anglia, Norwich, UK \\ ${ }^{2}$ School of Environmental Sciences, University of East Anglia, Norwich, UK \\ ${ }^{3}$ National Centres for Atmospheric Science, Reading, UK \\ ${ }^{4}$ Department of Geosciences/Program in Atmosphere and Ocean Science, Princeton University, Princeton, USA
}

Correspondence to: M. Joshi (m.joshi@uea.ac.uk)

Received: 12 June 2014 - Published in Geosci. Model Dev. Discuss.: 15 August 2014

Revised: 10 February 2015 - Accepted: 31 March 2015 - Published: 23 April 2015

\begin{abstract}
The IGCM4 (Intermediate Global Circulation Model version 4) is a global spectral primitive equation climate model whose predecessors have extensively been used in areas such as climate research, process modelling and atmospheric dynamics. The IGCM4's niche and utility lies in its speed and flexibility allied with the complexity of a primitive equation climate model. Moist processes such as clouds, evaporation, atmospheric radiation and soil moisture are simulated in the model, though in a simplified manner compared to state-of-the-art global circulation models (GCMs). IGCM4 is a parallelised model, enabling both very long integrations to be conducted and the effects of higher resolutions to be explored. It has also undergone changes such as alterations to the cloud and surface processes and the addition of gravity wave drag. These changes have resulted in a significant improvement to the IGCM's representation of the mean climate as well as its representation of stratospheric processes such as sudden stratospheric warmings. The IGCM4's physical changes and climatology are described in this paper.
\end{abstract}

\section{Introduction}

In order to better understand the physical processes that underpin climate and climate change, it is necessary to examine not only state-of-the-art climate models but also simpler models which can have fewer degrees of freedom. In such a manner, commonly referred to as the hierarchy of models approach, a more robust picture of the causative mechanisms underlying climate processes can emerge. This paper describes the IGCM4 (Intermediate Global Circulation Model 4), which is the latest incarnation of a collection of simplified climate models, collectively and usually referred to as "Reading IGCM" models, after the institution where much of their development has taken place.

The rationale for such a model in the hierarchy of potential model codes is now addressed. Understanding key scientific questions related to climate and climate changes relies on understanding processes within the atmosphere, whose complex and nonlinear nature entails the use of global circulation models. However, understanding such complex processes in models is extremely challenging since unpicking processes within state-of-the-art climate circulation models can be extremely difficult given their complexity - especially when their computational demands are taken into account, leading to limits in both integration times and data storage.

Having said that, it is necessary for models to be complex enough to simulate the processes that are relevant to understanding a given question of interest. This is the niche which intermediate circulation models such as the IGCM occupies. This niche consists of models that are complex enough in terms of dynamical processes to represent a wide variety of processes from monsoonal circulations to extratropical storm tracks. However, their relative simplicity compared to state-of-the-art climate models that are employed by the Intergovernmental Panel on Climate Change (henceforth IPCC) enables process-level understanding to become more tractable because of (a) computational speed enabling long integrations or large ensemble members, and (b) flexibility and ease of use enabling the examination of idealised scenarios. Examples in which the IGCM4 might be used are the following: conducting integrations of idealised perturbations to boundary conditions such as sea-surface temperature, topography, or continental distributions; conducting ensem- 
bles of multi-century integrations to collect robust statistics of small-amplitude responses to particular forcings.

The base model which IGCM4 will be compared with is the so-called IGCM3 (Forster et al., 2000). The model has had many incremental updates since IGCM3, but since that was the last documented model and climatology, all improvements to IGCM4 are described with respect to IGCM3.

The IGCM has a number of configurations which are briefly described here in order to clarify where IGCM4 sits in relation to the others. IGCM1 is a spectral primitive equation model which can be run in global or hemispheric modes and is based on the spectral model of Hoskins and Simmons (1975). The vertical coordinate is the $\sigma$ terrainfollowing coordinate, where $\sigma=$ pressure/surface pressure. Diabatic processes in IGCM1 include spectral hyperdiffusion to remove noise at small scales, linear or "Newtonian" relaxation to a reference temperature state and linear or "Rayleigh" friction at any number of model layers. Examples of research conducted with this configuration are studies of baroclinic life cycles on Earth (Hoskins and Simmons, 1975; James and Gray, 1986; Thorncroft et al., 1993) and Mars (Collins and James, 1995), as well as studies of the stationary circulation on Earth (Valdes and Hoskins, 1991), Mars (Joshi et al., 1994) and other planets (Joshi et al., 1997).

In IGCM2, the linear diabatic processes in IGCM1 are replaced by more realistic nonlinear diffusive processes. Radiative processes are parameterised simply using a prescribed surface temperature and a constant cooling rate of $1.25 \mathrm{~K} \mathrm{day}^{-1}$ representing infrared radiation to space. The effects of moisture are included in IGCM2, necessitating the inclusion of evaporation, parameterisation of deep and shallow convection and the potential for moisture transport. Such a configuration represents moist processes allowing the study of tropical regions and has accordingly been used in studies of mesoscale tropical dynamics and circulation (Cornforth et al., 2009).

IGCM3 is a full climate model in which the prescribed surface can be replaced by one or both of a two-level interactive land surface and a slab or "q-flux" ocean model. The constant radiative cooling is replaced by a radiative scheme which calculates clear sky fluxes in two visible bands and six infrared bands and accounts for the radiative effects of clouds. This model is described fully in an appendix to Forster et al. (2000). This configuration has been used in many studies of tropospheric climate (Forster et al., 2000; Joshi et al., 2003) and stratospheric climate (Rosier and Shine, 2000; Winter and Bourqui, 2011a, b). A coupled ocean-atmosphere model (FORTE) has been created in the past by coupling the IGCM3 to the MOMA ocean model (e.g. Sinha et al., 2012). A similar process is underway for IGCM4, and the resulting coupled model is the subject of an accompanying paper.

We now set out the climatology of the new IGCM4 model in addition to changes since the last published detailed version IGCM3. Section 2 details changes since IGCM3, Sect. 3 details the new model climatology, and Sect. 4 details the climatic performance of the IGCM4.

\section{Model changes from IGCM3}

\subsection{IGCM4 configurations}

IGCM4 exists in two standard configurations: a spectral truncation of T42 (having a $128 \times 64$ horizontal grid) and 20 layers in the vertical, denoted T42L20, which is the standard configuration for studies of the troposphere and climate, and T42L35, which enables study of the stratosphere on climate. In addition, a configuration of T170L20, which enables study of mesoscale phenomena such as weather fronts and tropical waves, is also under development, but its description is beyond the scope of this paper. The L20 and L35 configurations reach from the surface to 50 and $0.1 \mathrm{hPa}$ respectively (Fig. 1). The lowest 19 model layers in each configuration have exactly the same values so that only the stratosphere is different, enabling more traceability when comparing different model configurations.

The spectral code is parallelised using a so-called 2-D decomposition (Foster and Worley, 1997; Kanamitsu et al., 2005). In a 2-D decomposition, two of the three dimensions are divided across the processors, and so there is a column and row of processors, with the columns divided across one dimension and the rows across another. Compared with a 1$\mathrm{D}$ decomposition, a 2-D decomposition increases the number of transpositions that need to be made to go from spectral space to grid space and back again. However the advantage is that each transposition is only amongst processor elements (henceforth PEs) either on the same column or the same row. Any transposition for 1-D decomposition requires all the PEs to communicate with one another, which increases the size of buffers passed between PEs, communication latency and slows down the model. Han and Juang (2004) found that a 2-D decomposition is about twice as fast as a 1-D decomposition. More details on the decomposition are given on the IGCM website (Stringer, 2012)

The model's performance on a parallel cluster using an Intel compiler and MPI parallelisation libraries is as follows: T42L35: 75 model years per day on 32 processors (96 time steps per day); T42L20: 200 model years per day on 32 processors (72 time steps per day).

\subsection{Surface and boundary layer processes}

Over land, each grid point has a land-surface type based on present-day observations: there are eight types (ice, inland water, forest, grassland, agriculture, tundra, swamp, desert). Each land-surface type has its own value for snowfree albedo $A$, snow-covered albedo $S$, the height (in metres) at which total albedo reaches $(A+S) / 2$ and roughness length. The values of these quantities for each surface type are shown in Table 1. 


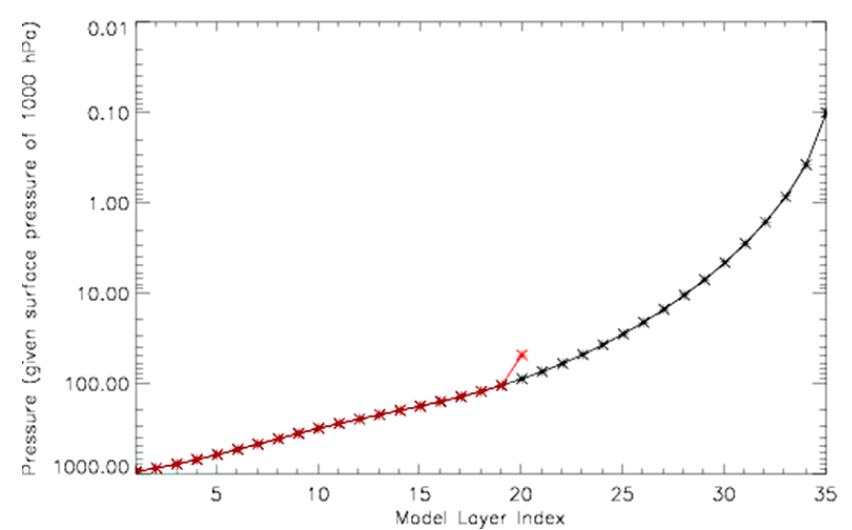

Figure 1. Model layer index vs. pressure (for a surface pressure of $1000 \mathrm{hPa}$ ) for the 35-layer model (black) and the 20-layer model (red). Note that the lowest 19 layers are exactly the same for both configurations.

Whenever snowmelt occurs in the model, the snowmelt moistens soil so that the soil water is two-thirds of the saturated value. This is a very simple parameterisation of snowmelt percolating through soil and helps to alleviate warm biases in late spring and summer in eastern Eurasia, consistent with more complex climate models such as HadGEM2 (Martin et al., 2010).

A maximum effective depth for snow of $15 \mathrm{~m}$ exists to prevent slow drifts in heat capacity and hence temperature and energy balance, since there is no physics in the IGCM4 to represent the melting of ice fields at their bases. In addition, the "land ice" surface type has a fixed snow depth so that points diagnosed as "ice" are not subject to slowly emerging model biases in temperature appearing because of snow depth slowly eroding away over decades. At present, these fixed land-ice points are set to be Antarctica and Greenland.

The effect of sea ice in IGCM is implemented by assuming a linear change from 0 to $-2{ }^{\circ} \mathrm{C}$ in these surface properties: roughness, albedo and heat capacity. This replaces the sudden change of surface properties at $-2{ }^{\circ} \mathrm{C}$, which is unrealistic given partial ice cover in most oceans. It also removes a bias in that, while sea ice forms from saline water at $-2{ }^{\circ} \mathrm{C}$, it melts at $0{ }^{\circ} \mathrm{C}$, since ice is mostly composed of fresh water. A combination of ice and open water is therefore desirable between -2 and $0^{\circ} \mathrm{C}$.

The amount that surface heat fluxes can be amplified by convectively unstable conditions above their values at neutral or zero stability has been limited to 4.0. This value has been chosen to limit latent heat fluxes over the ocean and sensible heat fluxes over the land to better match observations, although it is still a simplification of more complex schemes that involve the Richardson number (e.g. Louis, 1979), since it is entirely stability-based.
Table 1. Values of surface characteristics for each surface type in IGCM4 (ice, inland water, forest, grassland, agriculture, tundra, swamp, desert).

\begin{tabular}{lrrrr}
\hline Surface type & $\begin{array}{r}\text { Albedo } \\
\text { Srew-covered } \\
\text { albedo }\end{array}$ & $\begin{array}{r}\text { Height when albedo } \\
\text { is snow-covered (m) }\end{array}$ & $\begin{array}{r}\text { Roughness } \\
\text { length }(\mathrm{m})\end{array}$ \\
\hline Ice & 0.8 & 0.8 & 0.05 & 0.03 \\
Inland water & 0.2 & 0.6 & 0.05 & 0.001 \\
Forest & 0.25 & 0.7 & 0.1 & 0.1 \\
Grassland & 0.25 & 0.8 & 0.1 & 0.05 \\
Agriculture & 0.25 & 0.8 & 0.1 & 0.05 \\
Tundra & 0.3 & 0.8 & 0.05 & 0.03 \\
Swamp & 0.2 & 0.8 & 0.05 & 0.03 \\
Desert & 0.3 & 0.8 & 0.05 & 0.03 \\
\hline
\end{tabular}

\subsection{Radiation, convection, clouds and aerosol}

The NIKOSRAD radiation scheme in IGCM3 (Forster et al., 2000) has been replaced with a modified version of the Morcrette radiation scheme (Zhong and Haigh, 1995) which was originally written for the ECMWF model. This is because the NIKOSRAD scheme was found to produce $2 \Delta z$ oscillations under certain conditions in the stratosphere. A transitional version of IGCM3, called IGCM3.1, has existed with the Morcrette radiation scheme for some time, and many climatic (e.g. Bell et al., 2009; Cnossen et al., 2011) and climate-chemistry (e.g. Highwood and Stevenson, 2003; Taylor and Bourqui, 2005) studies have been conducted with it. The Morcrette radiation scheme has a representation of $\mathrm{O}_{3}$ absorption of UV between 0.12 and $0.25 \mu \mathrm{m}$, two visible bands $(0.25-0.68,0.68-4 \mu \mathrm{m})$ and five infrared (henceforth IR) bands.

The radiatively active species in the IGCM are $\mathrm{H}_{2} \mathrm{O}, \mathrm{CO}_{2}$, $\mathrm{CH}_{4}, \mathrm{O}_{3}, \mathrm{~N}_{2} \mathrm{O}$, CFC-11 and CFC-12. $\mathrm{H}_{2} \mathrm{O}$ is advected selfconsistently in the model but prescribed above a seasonally varying climatological tropopause. $\mathrm{O}_{3}$ is specified from a zonally averaged climatology ( $\mathrm{Li}$ and Shine, 1995), which is then interpolated to model levels. All other gases are assumed to be well-mixed throughout the GCM domain and are easily changed via a namelist.

The solar constant in IGCM4 is $1365 \mathrm{~W} \mathrm{~m}^{-2}$, which is more consistent with observations than the older value of $1376 \mathrm{~W} \mathrm{~m}^{-2}$ in IGCM3 and IGCM3.1. The ocean albedo $\mathrm{A}_{o}$ varies with latitude $\varphi$ in this manner:

$A_{o}=0.45-0.30 \cos \varphi$.

This is a simple parameterisation of the effects of aerosols and solar zenith angle on albedo based on observations so that at the Equator $A_{o}=0.15$, increasing to 0.3 at $60^{\circ} \mathrm{S} / \mathrm{N}$.

The convection scheme in the IGCM4 is identical to that described in Forster et al. (2000) and is based on the scheme of Betts (1986), with separate adjustment processes for shallow and deep convection; the adjustment process for deep convection takes place over $3 \mathrm{~h}$ as in Forster et al. (2000). Rainout of shallow convective precipitation is now allowed in IGCM4 over a timescale of $6 \mathrm{~h}$. This rainout helps to 
slow down the Hadley circulation whilst removing some of the shallow convective cloud that occurs over subtropical regions. Stratiform precipitation is as in Forster et al. (2000): grid-scale supersaturation is removed. Above a grid point relative humidity (henceforth $\mathrm{RH}$ ) of 0.8 , clouds are formed whose fraction $F$ is given by $F=((\mathrm{RH}-0.8) / 0.2)^{2}$. No cloud can form in the very lowest model layer.

The clouds have been tuned to better match observations of outgoing infrared radiation and downward surface solar radiation: the cloud base fraction for deep convective cloud is 4 times the fraction at all other levels, which is consistent with observed convective cloud profiles (Slingo, 1987). A version of the Kawai and Inoue (2006) parameterisation for marine stratocumulus cloud has also been implemented in IGCM4. This diagnoses low cloud at ocean points depending on the stability of the lowest two model sigma half layers (i.e. between the surface and layer 1 and between layer 1 and layer 2) and deposits cloud in the second-to-lowest model layer if diagnosed.

Aerosols are not in the standard IGCM4: their effect on surface temperatures have been parameterised by slightly raising the albedo of land and ocean by 0.05 . This is because even CMIP5 GCMs have trouble accurately representing the forcing due to different types of aerosol. In addition, even the aerosol scheme in the IGCM only deals with the direct effect, not the different indirect effects such as cloud lifetime and particle size that are also present in reality. However, both specific case studies of tropospheric and stratospheric aerosols have been studied using IGCM3.1 (Highwood and Stevenson, 2003; Ferraro et al., 2014), so future study using IGCM4 remains technically very feasible.

\subsection{Stratosphere}

A simple gravity wave drag scheme based on Lindzen (1981) had previously been implemented in both IGCM1 (Joshi et al., 1995) and IGCM3 (Cnossen et al., 2011). The IGCM4 scheme is as above but calculates drag based on orographic drag, as well as two non-orographic modes having horizontal phase speeds of $\pm 10 \mathrm{~m} \mathrm{~s}^{-1}$. The orographic drag source amplitude is the magnitude of the zonal wind in the lowest model layer multiplied by the subgrid-scale standard deviation of topography; the non-orographic source amplitude is the magnitude of the zonal wind in the lowest model layer multiplied by a constant value of $90 \mathrm{~m}$.

Stratospheric water vapour (henceforth SWV) is calculated by adding a fixed value ( 3 ppmv) onto an amount calculated by a parameterisation that considers the stratospheric radiative effects of changing tropospheric methane concentrations. Methane oxidation in the stratosphere depends on the stratospheric chemical environment and stratospheric residence time. While both the chemical environment and the Brewer-Dobson circulation may change in a changing climate, coupled chemistry-climate model integrations show that their effects on stratospheric methane (and hence on SWV) are small compared to the effect of the changes in methane entering the stratosphere (Eyring et al., 2010), which in turn is given by the change in average tropospheric methane to a good approximation. Hence, the impact of changing tropospheric methane can be approximated by calculating the stratospheric distribution of the fraction of oxidised methane, which then is multiplied by the amount of tropospheric methane to give the change in stratospheric methane and its contribution to changes in SWV. We define the oxidised fraction $\beta$ :

$\beta(\varphi, z)=1-\mathrm{CH}_{4}(\varphi, z) / \mathrm{CH}_{4}$ troposphere,

where $z$ is altitude, $\varphi$ is latitude, and any longitudinal variation is assumed to be averaged. $\mathrm{CH}_{4}(\varphi, z)$ is obtained from satellite measurements by the Halogen Occultation Experiment (HALOE, Russell III et al., 1993) over the period 19952005. Assuming that two water molecules form for each methane molecule, the water vapour change occurring over a given time interval is given by combining the change in $\mathrm{CH}_{4}$ over the same time interval with the scaling factor $\beta$ in a similar manner to Fueglistaler and Haynes (2005) giving

$\mathrm{dH}_{2} \mathrm{O}(\varphi, z)=2 \cdot \beta(\varphi, z) \cdot \mathrm{dCH}_{4}$ troposphere.

These calculated SWV anomalies are then supplied to the IGCM to allow calculation of the influence of this additional effect on climate. This approach provides excellent predictions of stratospheric methane changes in CCMVal2 models for the period 1960-2008 (REF-1B runs) (Eyring et al., 2010).

Figure $2 \mathrm{~b}$ shows an analytical approximation to this distribution, which is then used to calculate $\beta$. The effect is demonstrated by showing the SWV perturbation in ppmv for pre-industrial $\mathrm{CH}_{4}$ concentrations of $0.75 \mathrm{ppmv}$ (bottom left), and potential future concentrations of $\mathrm{CH}_{4}$ of $2.5 \mathrm{ppmv}$ (bottom right), as might be expected in the mid 21st century under the Representative Concentration Pathway (RCP) 8.5 scenario (Holmes et al., 2013). For reference the background SWV concentration to which this perturbation is added is 3 ppmv.

\section{Model evaluation}

\subsection{Surface and top-of-atmosphere model climatology}

The following results are all from the most commonly used configuration of the IGCM4: sea surface temperature (henceforth SST) is prescribed as a monthly varying climatology based on ERA-40 reanalysis (Forster et al., 2000), but land temperature is calculated self-consistently from surface fluxes at each time step. For this section, the 20-layer T42L20 model has been used, which has been integrated for 100 model years in total.

Figure 3 shows the comparison between NCEP-DOE Reanalysis 2 (Kanamitsu et al., 2002) and IGCM4 surface 

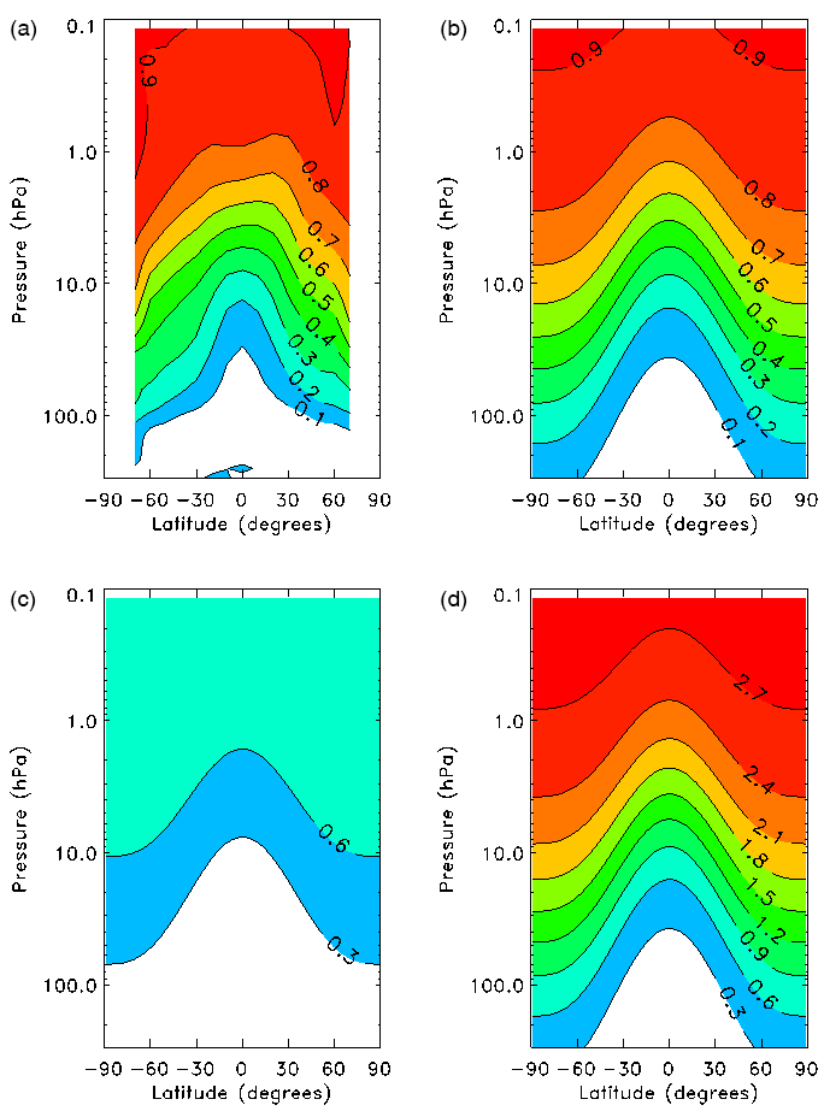

Figure 2. The fraction of oxidised methane (which is linked to $\mathrm{CH}_{4}$ concentration - see Eq. 1) derived from HALOE data (a); the analytical approximation which extends to the poles (b); the perturbation to stratospheric water vapour (SWV) (ppmv) in pre-industrial conditions, when $\mathrm{CH}_{4}$ is $0.75 \mathrm{ppmv}$ (c); the perturbation to $\mathrm{SWV}$ (ppmv) if $\mathrm{CH}_{4}$ is increased to $2.5 \mathrm{ppmv}(\mathbf{d})$.

temperature. During boreal winter (December-February, or DJF), Fig. 3e shows that the model displays a slight cold bias in northern Eurasia and a warm bias in the tropical regions and Antarctica. The bias is mostly below $10 \mathrm{~K}$ in amplitude, which is good for intermediate models of this type. The boreal summer response (June-August, or JJA) is shown in Fig. 3f. Here, a warm bias is present over most of the land surface. The warm bias in both summer hemispheres is likely due to an absence of aerosols in the IGCM, especially over North Africa and Australia where high amounts of dust occur in reality. However, even during JJA the magnitude of the bias is less than $10 \mathrm{~K}$ almost everywhere, which is reasonable when compared to biases even in CMIP5 models (e.g. Flato et al., 2013, Fig. 9.2). Both ice caps display too large a seasonal cycle, which we attribute to the simplicity of the snow scheme in the model, which has no facility for changing density or conductivity when snow is compacted into ice. This could be a source for future model improvement.

Figure $4 \mathrm{c}$ shows the precipitation bias in DJF in the IGCM compared to the CMAP data set (Xie and Arkin, 1997) shown
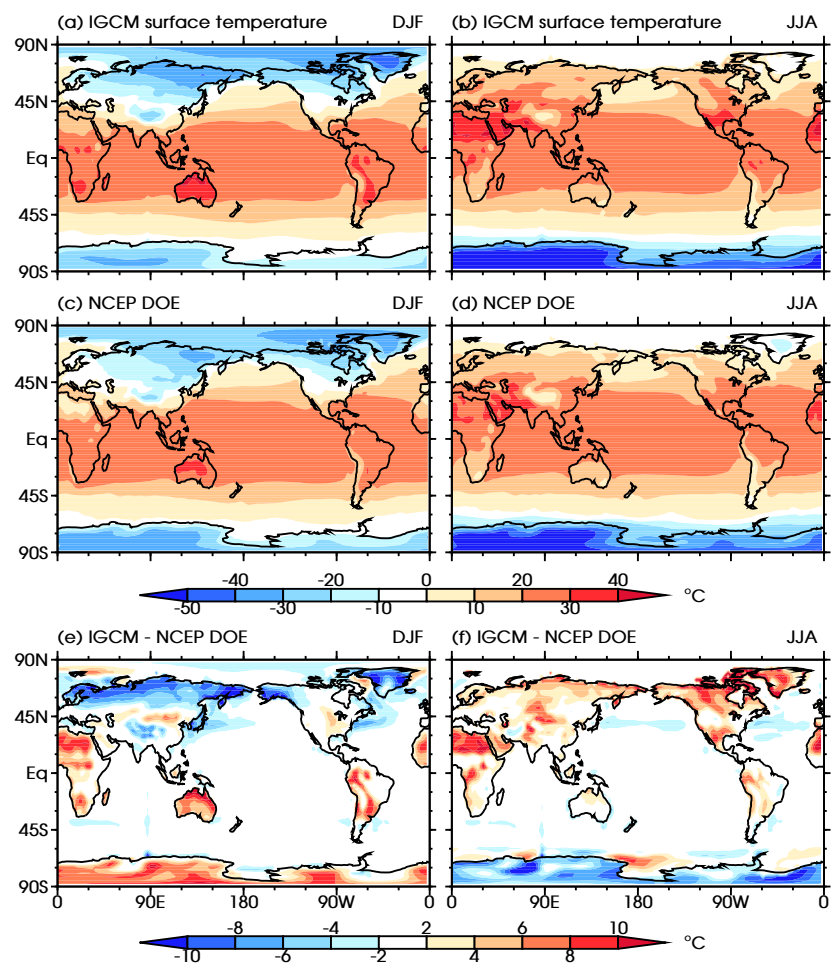

Figure 3. Surface temperature $\left({ }^{\circ} \mathrm{C}\right)$ in IGCM4 (a, b), NCEP-DOE reanalysis (c, d) and difference between IGCM4 and reanalysis (e, f). In all cases the left-hand panels display results for the DJF season, and the right-hand panels display results for JJA season. For the reanalysis a mean over the years 1979-2013 is taken.

in Fig. 4a. In general the comparison is quite good, with the major convergence zones (as diagnosed by the $4 \mathrm{~mm}_{\text {day }}{ }^{-1}$ contour in black) being represented quite well. As a guide to the IGCM's performance in the context of other models, the mean \pm 1 standard deviation precipitation bias amongst a subset of models present in the CMIP5 archive being used for the UN Intergovernmental Panel on Climate Change's 5th assessment report (IPCC AR5) is also shown (Fig. 4d and f respectively): the comparison is for the CMIP5 model configuration using prescribed "AMIP" SSTs, since coupled oceanatmosphere biases tend to worsen model performance.

The IGCM's precipitation bias (Fig. 4c) lies within 1 standard deviation of the AMIP ensemble biases; for instance the dry bias in the Southern Pacific Convergence Zone (SPCZ) in the IGCM (Fig. 4c) is $2-5 \mathrm{~mm} \mathrm{day}^{-1}$, which is similar in magnitude to the mean minus 1 standard deviation, suggesting that the IGCM's performance in this region is within the envelope of state-of-the-art GCMs forced by observed SSTs.

Figure 5 is the same as Fig. 4 but for the JJA period. There are some notable wet biases in IGCM4 as shown by Fig. 5c, particularly in the northern Indian Ocean and Central American regions; however, such wet biases are not outside the envelope of the CMIP5 ensemble when comparing the IGCM to the "mean plus 1 standard deviation" (Fig. 5f). Thus, for 

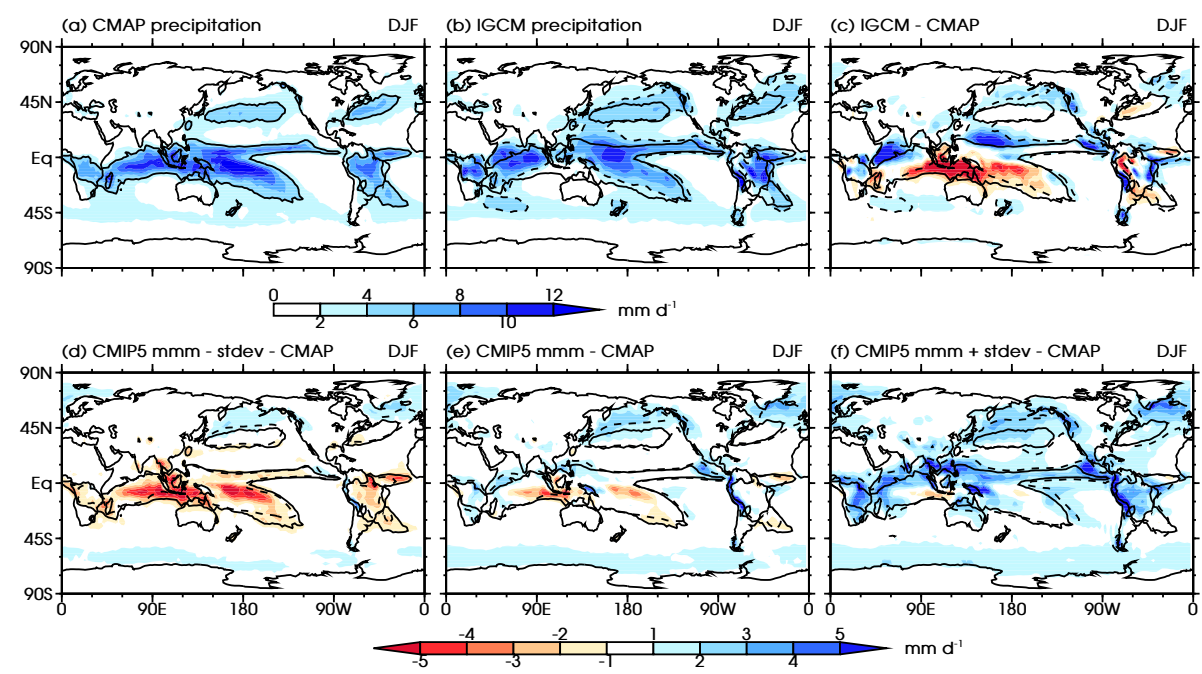

Figure 4. DJF season mean precipitation $\left(\mathrm{mm} \mathrm{day}^{-1}\right.$ ) in CMAP (a), IGCM4 (b) and difference between IGCM4 and CMAP (c). (e) shows the difference between a multi-model mean of an ensemble of CMIP5 GCMs integrated using AMIP SSTs and CMAP; (f) as for (e) but for the multi-model mean minus 1 standard deviation; (g) as for (e) but for the multi-model mean plus 1 standard deviation. In all cases the solid line is the $4 \mathrm{~mm} \mathrm{day}^{-1}$ contour in CMAP and the dashed line is the same contour in the model of the subfigure. (a, b) are based on the top colour bar, (c)-(f) are based on the bottom colour bar. The CMIP5 models used in the ensemble are ACCESS1.0, ACCESS1.3, BCC-CSM1.1, BCC-CSM1.1(m), BNU-ESM, CanCM4, CCSM4, CESM1(CAM5), CCMC-CM, CNRM-CM5, CSIRO-Mk3.6.0, FGOALSg2, GFDL-CM3, GISS-E2-R, HadGEM2-AO, INM-CM4, IPSL-CM5A-LR, IPSL-CM5A-MR, IPSL-CM5B-LR, MIROC5, MPI-ESM-LR, MPI-ESM-MR, MRI-CGCM3 and NorESM1-M. The mean is over the years 1979-2005.
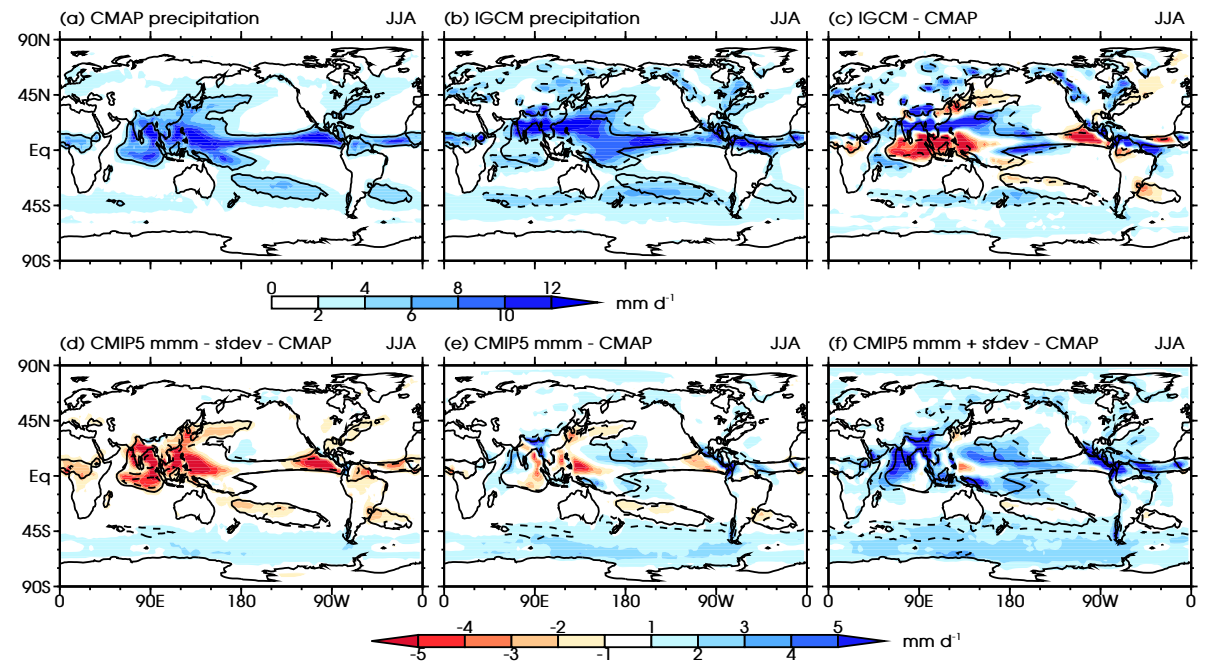

Figure 5. As for Fig. 4 but during the JJA season.

the JJA season as well as the DJF season, the precipitation bias in IGCM4 is within the range of state-of-the-art GCMs forced by observed SSTs, which provides a good justification for the use of IGCM4 as a simplified climate model.

The interaction of precipitation, cloud and radiation can be studied by comparing the outgoing long-wave radiation (OLR) field with observations (Liebmann and Smith, 1996), which is shown in Fig. 6. Figure 6e shows that the IGCM broadly simulates OLR quite well, with some differences between model and observations in the maritime continent re- gion. During JJA (Fig. 6f), there is a positive bias in OLR over the Indian Ocean (Fig. 6f), consistent with a slight dry bias there (Fig. 4c). The top-of-atmosphere energy imbalance in the IGCM is approximately $1-2 \mathrm{~W} \mathrm{~m}^{-2}$, which is similar to other climate models (e.g. Roeckner et al., 2006). 

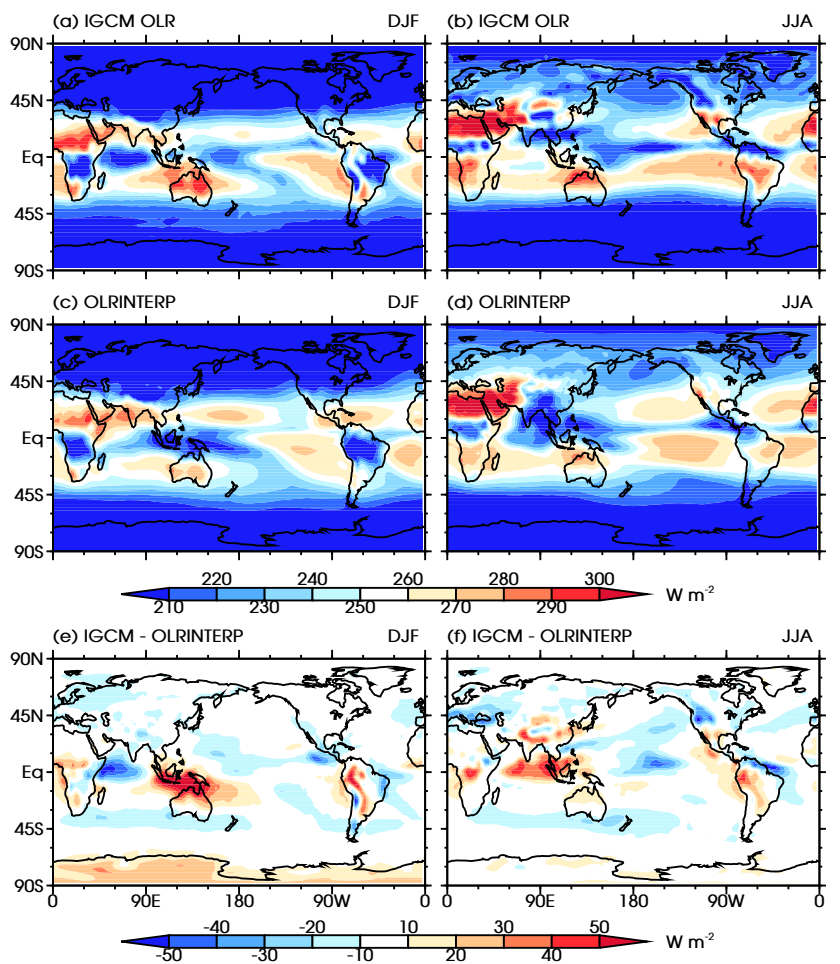

Figure 6. Outgoing long-wave radiation (OLR; $\mathrm{W} \mathrm{m}^{-2}$ ) in IGCM4 (a, b), interpolated OLR data set $(\mathbf{c}, \mathbf{d})$ and difference between IGCM4 and interpolated OLR data set (Liebmann and Smith, 1996) (e, f). In all cases the left-hand panels display results for the DJF season, and the right-hand panels display results for JJA season. For the interpolated OLR data set a mean over the years 19792011 is taken.

\subsection{Zonal mean climatology and stratospheric performance}

For this section, both 20-layer T42L20 and 35-layer T42L35 configurations are described; the latter has been integrated for 200 model years in total, in order to average out the effect of stratospheric variability. Figure 7 shows the zonally averaged temperature structure in IGCM4 for the two solstitial seasons compared to data from the ERA-40 reanalysis (Uppala et al., 2005). In both seasons the lower stratosphere in both L20 and L35 configurations is too cold in the tropics and the winter extratropics by $5-10 \mathrm{~K}$. Elsewhere, biases are smaller than $10 \mathrm{~K}$ apart from near the summer stratopause, perhaps due to deficiencies in the ozone heating in IGCM4. These errors are comparable models that represent the stratosphere (e.g. Eyring et al., 2006).

A comparison between the zonally averaged zonal wind in IGCM4 and ERA-40 is shown in Fig. 8 and, like Fig. 7, also shows good agreement, perhaps not surprisingly for a field that is expected to be in large-scale thermal balance with temperature. In both L20 and L35 configurations, the Southern Hemisphere tropospheric jet stream is slightly equatorward of the jet in ERA-40 as shown by the dipole pattern in
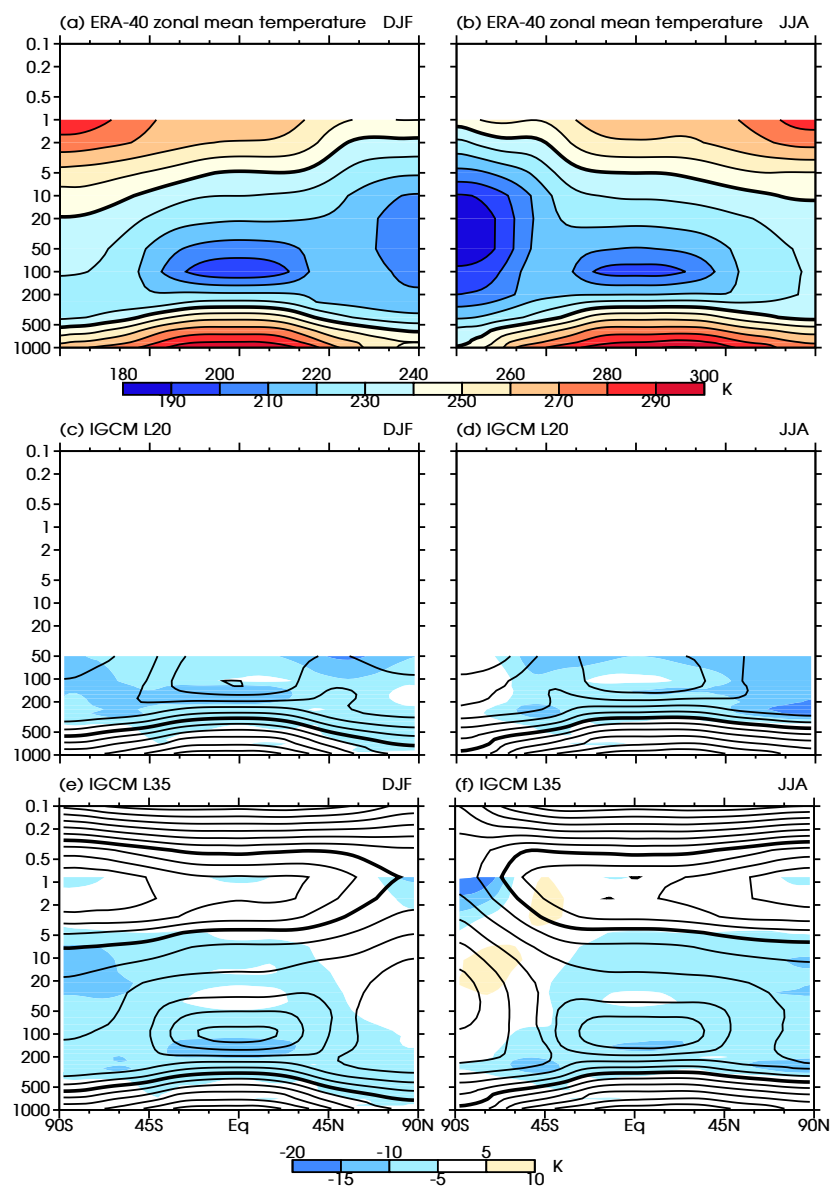

Figure 7. Zonally averaged temperature (K) in ERA (a, b), difference between IGCM4 L20 and ERA (c, d) and difference between IGCM4 L35 and ERA $(\mathbf{e}, \mathbf{f})$ in colour shading. In all subfigures contours show the total zonal mean temperature field (contour interval is $10 \mathrm{~K}, 240 \mathrm{~K}$ contour thicker). In all cases the left-hand panels display results for the DJF season, and the right-hand panels display results for JJA season. For the reanalysis a mean over the years 1958-2002 is taken.

colours in Fig. 8c-f in this region. During DJF the Northern Hemisphere's tropospheric jet stream is slightly too strong in both L20 (Fig. 8c) and L35 (Fig. 8e) by $5 \mathrm{~m} \mathrm{~s}^{-1}$. In general, both L20 and L35 configurations display similar tropospheric biases in zonal wind.

During DJF, the strength of the stratospheric jet streams in the L35 configuration IGCM4 compares well to ERA-40 (Fig. 7e). In northern winter especially this is a sign that the joint effects of gravity wave drag and tropospheric wave forcing in IGCM4 are approximately of the right magnitude, since these two factors play a crucial role in controlling the strength of the DJF winter stratospheric jet stream. In JJA however the stratospheric jet stream is weaker and less tilted in the vertical than ERA-40 (Fig. 7f). This bias is likely due to the simplicity of the gravity wave drag scheme (see above) and might be removed by more tuning of the drag scheme - 


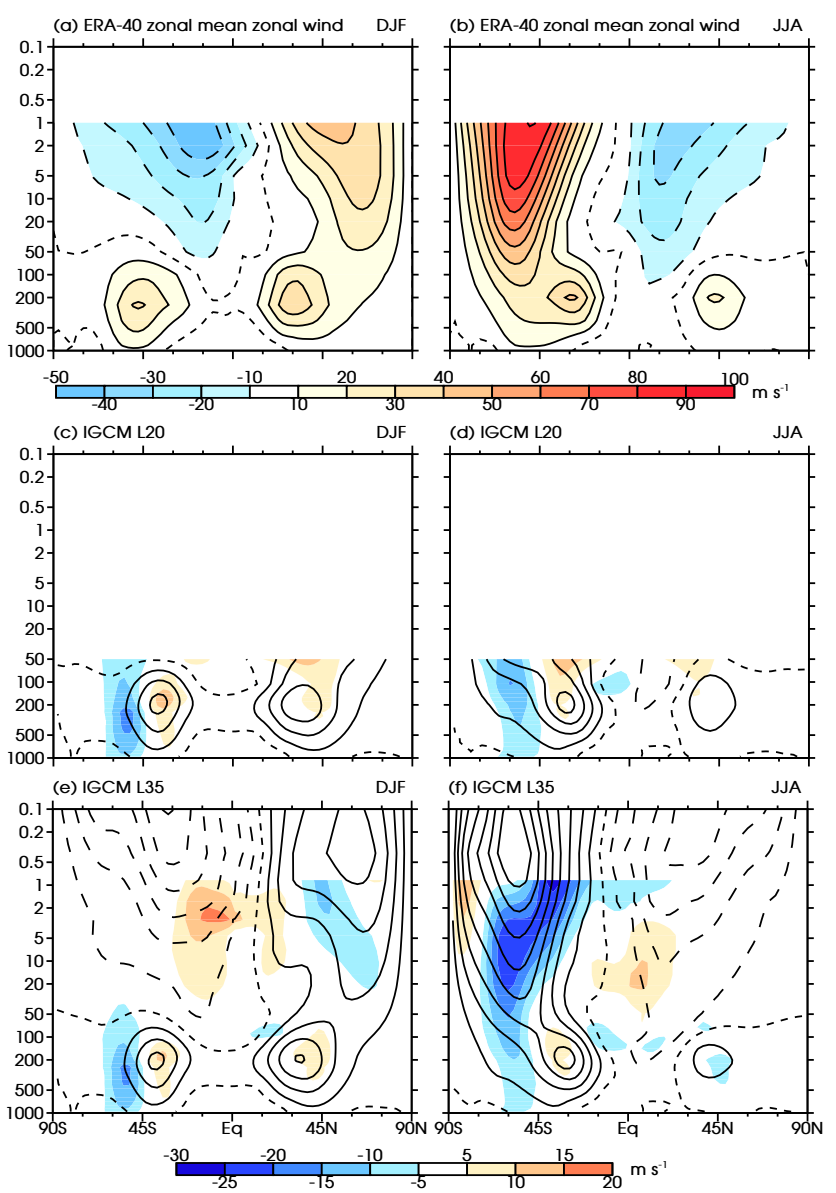

Figure 8. Zonally averaged zonal wind $\left(\mathrm{m} \mathrm{s}^{-1}\right)$ in ERA (a, b), difference between IGCM4 L20 and ERA (c, d) and difference between IGCM4 L35 and ERA (e, f) in colour shading. In all subfigures contours show the total zonal mean zonal wind field (contour interval is $10 \mathrm{~m} \mathrm{~s}^{-1}$, negative contours dashed, zero contour dotted). In all cases the left-hand panels display results for the DJF season, and the right-hand panels display results for JJA season. For the reanalysis a mean over the years $1958-2002$ is taken.

but this would require more multi-century L35 integrations to ensure that tuning did not result in greater biases elsewhere: as such it is a source for future development.

The zonally asymmetric component of the circulation is apparent from Fig. 9, which shows the geopotential height eddy fields at 500 and $200 \mathrm{hPa}$. The IGCM4 reproduces the main features of the reanalysis with the standing wave patterns apparent in both model configurations, although the low-pressure anomaly in NE Asia is weaker in both model configurations compared to reanalysis. Both L35 and L20 configurations display a similar standing wave pattern at both pressure levels.

A key issue for stratospheric dynamics and its interplay with tropospheric climate, which is a primary use of this model, is that the stratospheric circulation, and phenomena such as sudden stratospheric warmings (henceforth SSWs)

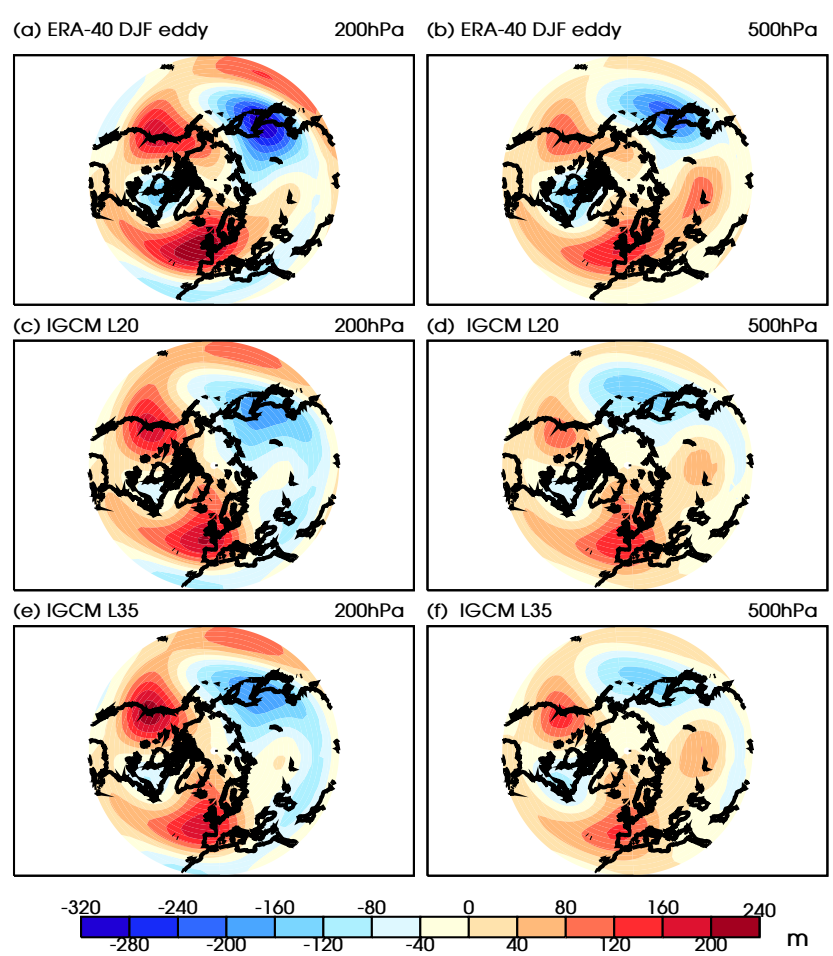

Figure 9. Geopotential height (m) DJF eddy fields for (a, b) $200 \mathrm{hPa}$ and $500 \mathrm{hPa}$ ERA-40 reanalysis respectively. The same for (c, d) IGCM4 L20 and (e, f) IGCM4 L35. For the reanalysis a mean over the years 1958-2002 is taken.

are simulated as well as other models. A 200-year-long integration of IGCM4 yielded $0.57 \mathrm{SSW}$ per year as diagnosed by the method of Charlton and Polvani (2007). This should be compared with 0.6 as diagnosed in reanalyses by Charlton and Polvani (2007), and $57 \%$ of the SSWs were categorised as "displacement" events using a vortex moment method based on Mitchell et al. (2011) and 43\% diagnosed as "split" events, again broadly consistent with reanalysis output, which suggests that just under half of SSWs can be categorised as "split" events (Charlton and Polvani, 2007). The timing of SSWs during boreal winter is shown in Fig. 10. Again, the timings are broadly consistent with reanalysis output, although there are somewhat more displacement events during March than diagnosed from reanalysis.

\section{Climate change and energy balance}

When coupled to a slab q-flux ocean model, IGCM4 has an equilibrium climate sensitivity when doubling $\mathrm{CO}_{2}$ from its pre-industrial concentration of $280 \mathrm{ppmv}$ of $2.1 \mathrm{~K}$. This sensitivity is slightly higher than the value of $1.6 \mathrm{~K}$ in IGCM3 (Joshi et al., 2003) and is likely due to the changes in cloud physics outlined above.

We have not performed simulations of a slab model for this paper because, although one effect of a slab ocean is 


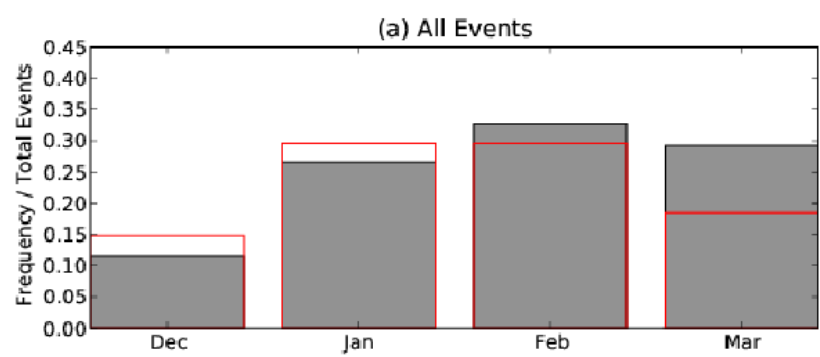

(b) Vortex Displacement Events

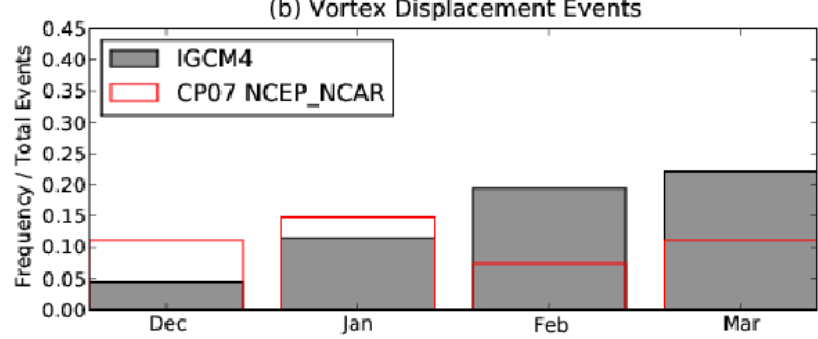

(c) Vortex Splitting Events

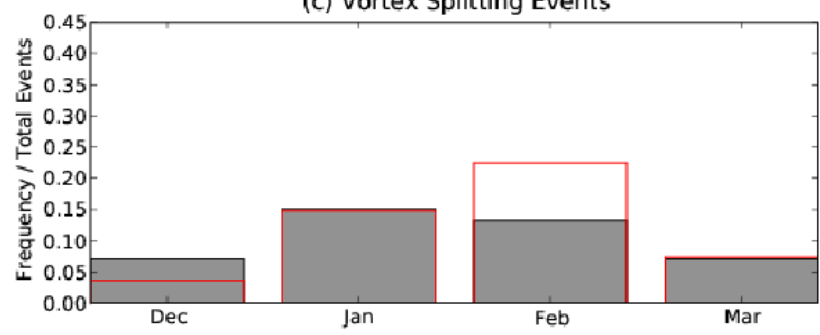

Figure 10. Distribution of sudden stratospheric warmings in boreal winter by month in the IGCM4 (filled grey boxes) and reanalysis (red outline boxes; a), distribution of displacement-type warmings (b) and distribution of split-type warmings (c).

to change the characteristics of model interannual variability (as shown by Winter and Bourqui, 2011a), the nature of such changes will depend on the depth of the slab and how this depth changes seasonally and geographically: for instance in the North Atlantic Ocean the effective mixed layer depth changes from $50 \mathrm{~m}$ during summer to $500 \mathrm{~m}$ in winter. Moreover, the dynamic influence of the atmosphere on the ocean will also depend on the effective mixed layer depth of the ocean, or depth of the slab, as shown by O'Callaghan et al. (2014), as well as causing a dynamical ocean response (Zhai et al., 2014).

Because interannual variability is sensitive to slab ocean depth, and the IGCM has a constant slab depth, rather than one that varies seasonally and geographically, we have not discussed interannual variability in this paper. However, such a topic would be a source of useful research in the future for a configuration of the IGCM that had such a varying slab ocean model.
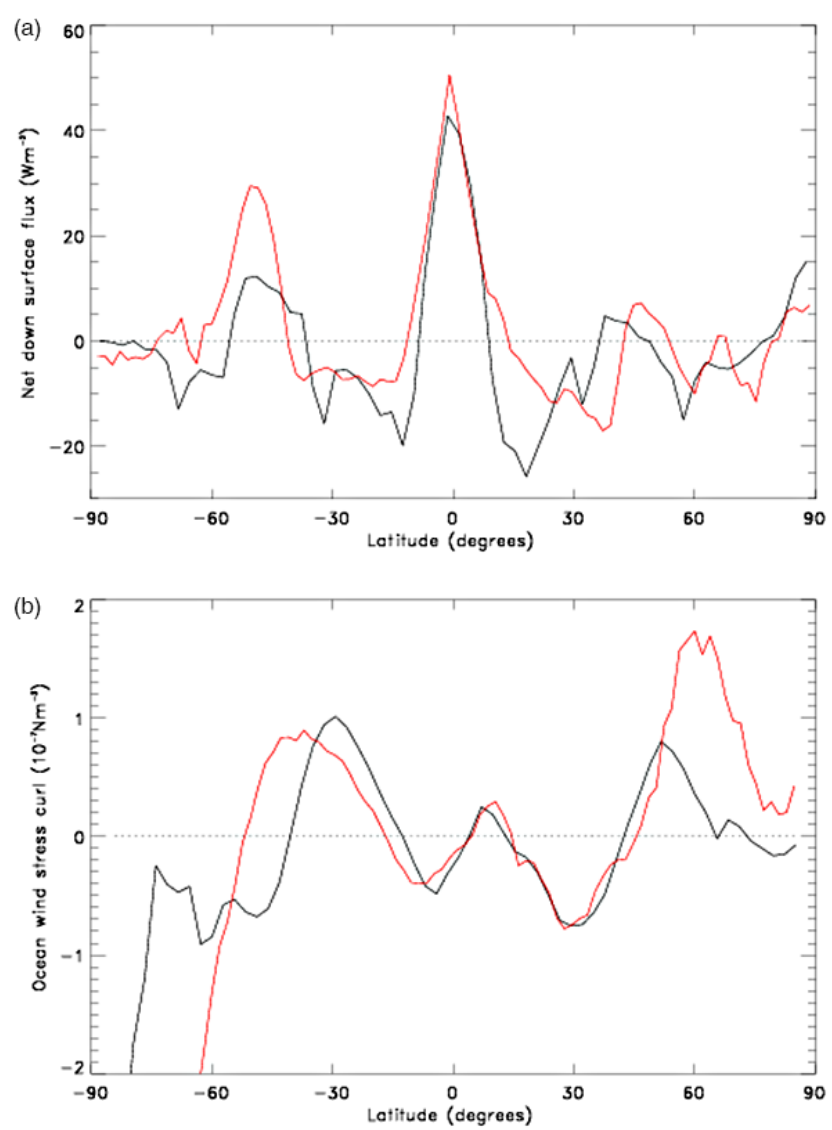

Figure 11. Annually averaged net downward zonal surface energy imbalance $\left(\mathrm{W} \mathrm{m}^{-2}\right)$ in IGCM4 (black) and NCEP reanalysis (red, a); wind stress curl $\left(10^{-7} \mathrm{Nm}^{-3}\right)$ in IGCM4 (black) and NCEP reanalysis (red, b).

As a first assessment of coupled model performance, the zonally averaged net surface energy imbalance and wind stress curl in IGCM4 are examined and compared to reanalysis, since large errors in these two fields will give errors in the dynamic and thermodynamic ocean responses respectively. Figure 11 shows that the broad patterns of response are similar in both model and reanalysis. In equatorial regions incoming solar radiation is not quite balanced by outgoing IR emission because of the presence of tropical convection and thick clouds, leading to positive values (see Fig. 11a); the intense rainfall associated with such convection is shown in Figs. $4 \mathrm{a}-\mathrm{c}$ and $5 \mathrm{a}-\mathrm{c}$. In subtropical regions, a lack of cloud leads to more IR emission and negative values in both reanalysis and IGCM4. The pattern of wind stress curl (see Fig. 11b) is indicative of the combined effects of midlatitude westerlies and subtropical and tropical trade winds, and it is similar in both model and reanalysis apart from the Southern Ocean westerlies being slightly too equatorward in the model and the Arctic, where the IGCM fails to reproduce large values associated with mesoscale circulations (e.g. Condron and 
Renfrew, 2013) that the model cannot represent given its horizontal resolution.

To summarise, we have presented the physical details and major climatological and dynamical features of the IGCM4 climate model. The model provides a fast alternative to conventional state-of-the-art GCMs while retaining the richness of dynamical behaviour allowed by the primitive equations of meteorology. As such the IGCM4 forms a useful part of the "hierarchy of models" approach needed to fully understand climate.

\section{Code availability}

The code is available to scientific researchers on request by emailing m.joshi@uea.ac.uk in the first instance. Websites detailing different IGCM configurations are given in Sect. 2.2. IGCM4 requires as a prerequisite a Fortran compiler, the nupdate code management utility and MPI routines for parallel integrations (although IGCM4 is designed to run on one processor).

Acknowledgements. Model simulations were carried out on the High Performance Computing Cluster supported by the Research and Specialist Computing Support service at the University of East Anglia. A. O'Callaghan acknowledges the support of the UK Natural Environment Research Council (NERC). OLR and CMAP precipitation data were provided by the NOAA/OAR/ESRL PSD, Boulder, Colorado, USA, from their website at http://www.esrl.noaa.gov/psd/. We acknowledge the assistance of M. Blackburn, D. Stevens, B. Sinha, A. Blaker, A. Ferraro, E. Highwood, K. Shine and C. Bell.

Edited by: D. Roche

\section{References}

Bell, C., Gray, L. J., Charlton-Perez, A., Joshi, M. M., and Scaife, A.: Stratospheric Communication of El Niño Teleconnections to European Winter, J. Climate, 22, 4083-4096, 2009.

Betts, A. K.: A new convective adjustment scheme 1. Observational and theoretical basis, Q. J. Roy. Meteorol. Soc., 112, 667-691, 1986.

Charlton, A. J. and Polvani, L. M.: A new look at stratospheric sudden warmings. Part I: Climatology and modeling benchmarks, J. Climate, 20, 449-469, 2007.

Cnossen, I., Lu, H., Bell, C. J., Gray, L. J., and Joshi, M. M.: Solar signal propagation: The role of gravity waves and stratospheric sudden warmings, J. Geophys. Res., 116, D02118, doi:10.1029/2010JD014535, 2011.

Collins, M. and James, I. N.: Regular baroclinic transient waves in a simplified global circulation model of the Martian atmosphere, J. Geophys. Res., 100, 14421-14432, 1995.

Condron, A. and Renfrew, I. A.: The impact of polar mesoscale storms on northeast Atlantic Ocean circulation, Nat. Geosci., 6, 34-37, 2013.
Cornforth, R. J., Hoskins, B. J., and Thorncroft, C. D.: The impact of moist process on the African easterly jet- African easterly wave system, Q. J. Roy. Meteor. Soc., 135, 894-913, 2009.

Eyring, V., Butchart, N., Waugh, D. W., Akiyoshi, H., Austin, J., Bekki, S., Bodeker, G. E., Boville, B. A., Brühl, C., Chipperfield, M. P., Cordero, E., Dameris, M., Deushi, M., Fioletov, V. E., Frith, S. M., Garcia, R. R., Gettelman, A., Giorgetta, M. A., Grewe, V., Jourdain, L., Kinnison, D. E., Mancini, E., Manzini, E., Marchand, M., Marsh, D. R., Nagashima, T., Newman, P. A., Nielsen, J. E., Pawson, S., Pitari, G., Plummer, D. A., Rozanov, E., Schraner, M., Shepherd, T. G., Shibata, K., Stolarski, R. S., Struthers, H., Tian, W., and Yoshiki, M.: Assessment of temperature, trace species, and ozone in chemistry-climate model simulations of the recent past, J. Geophys. Res., 111, D22308, doi:10.1029/2006JD007327, 2006.

Eyring, V., Shepherd, T. G., and Waugh, D. W. (Eds.): SPARC Report on the Evaluation of Chemistry-Climate Models, SPARC Report No. 5, WCRP-132, WMO/TD-No. 1526, SPARC, 2010.

Ferraro, A. J., Highwood, E. J., and Charlton-Perez, A. J.: Weakened tropical circulation and reduced precipitation in response to geoengineering, Environ. Res. Lett., 9, 014001, doi:10.1088/1748-9326/9/1/014001, 2014.

Flato, G., Marotzke, J., Abiodun, B., Braconnot, P., Chou, S. C., Collins, W., Cox, P., Driouech, F., Emori, S., Eyring, V., Forest, C., Gleckler, P., Guilyardi, E., Jakob, C., Kattsov, V., Reason, C., and Rummukainen, M.: Evaluation of Climate Models, in: Climate Change 2013: The Physical Science Basis. Contribution of Working Group I to the Fifth Assessment Report of the Intergovernmental Panel on Climate Change, edited by: Stocker, T. F., Qin, D., Plattner, G.-K., Tignor, M., Allen, S. K., Boschung, J., Nauels, A., Xia, Y., Bex, V., and Midgley, P. M., Cambridge University Press, Cambridge, United Kingdom and New York, NY, USA, 2013.

Forster, P. M. De F., Blackburn, M., Glover, R., and Shine, K. P.: An examination of climate sensitivity for idealised climate change experiments in an intermediate general circulation model, Clim. Dynam., 16, 833-849, 2000.

Foster, I. T. and Worley, P. H.: Parallel Algorithms For The Spectral Transform Method, SIAM J. Sci. Comput., 18, 806-837, doi:10.2172/10168301, 1997.

Fueglistaler, S. and Haynes, P. H.: Control of interannual and longer-term variability of stratospheric water vapor, J. Geophys. Res., 110, D24108, doi:10.1029/2005JD006019, 2005.

Han, J. and Juang, H.-M.: Development of Fully Parallelized Regional Spectral Model at NCEP, 20th Conference on Weather Analysis and Forecasting, Seattle, Am. Meteorol. Soc., available at: https://ams.confex.com/ams/pdfpapers/71807.pdf (last access: 21 April 2015), 2004.

Highwood, E.-J. and Stevenson, D. S.: Atmospheric impact of the 1783-1784 Laki Eruption: Part II Climatic effect of sulphate aerosol, Atmos. Chem. Phys., 3, 1177-1189, doi:10.5194/acp3-1177-2003, 2003.

Holmes, C. D., Prather, M. J., Søvde, O. A., and Myhre, G.: Future methane, hydroxyl, and their uncertainties: key climate and emission parameters for future predictions, Atmos. Chem. Phys., 13, 285-302, doi:10.5194/acp-13-285-2013, 2013.

Hoskins, B. J. and Simmons, A. J.: A multilayer spectral model and the semi-implicit method, Q. J. Roy. Meteor. Soc., 101, 637-655, 1975. 
James, I. N. and Gray, L. J.: Concerning the effect of surface drag on the circulation of a baroclinic planetary atmosphere, Q. J. Roy. Meteor. Soc., 114, 619-637, 1986.

Joshi, M. M., Lewis, S. R., Read, P. L., and Catling, D. C.: Western boundary currents in the atmosphere of Mars, Nature, 367, 548$552,1994$.

Joshi, M. M., Lawrence, B. N., and Lewis, S. R.: Gravity wave drag in three-dimensional atmospheric models of Mars, J. Geophys. Res., 100, 21235-21245, 1995.

Joshi, M. M., Haberle, R. M., and Reynolds, R. T.: Simulations of the atmospheres of synchronously rotating terrestrial planets orbiting M-dwarfs: conditions for atmospheric collapse and implications for habitability, Icarus, 29, 450-465, 1997.

Joshi, M. M., Shine, K. P., Ponater, M., Stuber, N., Sausen, R., and $\mathrm{Li}, \mathrm{L}$.: A comparison of climate response to different radiative forcings in three general circulation models: Towards an improved metric of climate change, Clim. Dynam., 20, 843-854, 2003.

Kanamitsu, M., Ebisuzaki, W., Woollen, J., Yang, S.-K., Hnilo, J. J., Fiorino, M., and Potter, G. L.: NCEP-DOE AMIP-II Reanalysis (R-2), B. Am. Meteorol. Soc., 83, 1631-1643, 2002.

Kanamitsu, M., Kanamaru, H., Cui, Y., and Juang, H.: Parallel Implementation of the Regional Spectral Atmospheric Model. Scripps Institution of Oceanography, University of California at San Diego, and National Oceanic and Atmospheric Administration for the California Energy Commission, PIER EnergyRelated Environmental Research, CEC-500-2005-014, 2005.

Kawai, H. and Inoue, T.: A simple parameterisation scheme for subtropical marine stratocumulus, SOLA, 2, 017-020, doi:10.2151/sola.2006-005, 2006.

Li, D. and Shine, K. P.: A 4-Dimensional Ozone Climatology for UGAMP Models, UGAMP Internal Report No. 35, April 1995.

Liebmann, B. and Smith, C. A.: Description of a complete (interpolated) outgoing longwave radiation dataset, B. Am. Meteorol. Soc., 77, 1275-1277, 1996.

Lindzen, R. S: Turbulence and stress owing to gravity wave and tidal breakdown, J. Geophys. Res., 86, 9707-9714, 1981.

Louis, J. F.: A parametric model of vertical eddy fluxes in the atmosphere, Bound.-Lay. Meteorol., 17, 187-202, 1979.

Martin, G. M., Milton, S. F., Senior, C. A., Brooks, M. E., Ineson, S., Reichler, T., and Kim, J.: Analysis and Reduction of Systematic Errors through a Seamless Approach to Modeling Weather and Climate, J. Climate, 23, 5933-5957, 2010.

Mitchell, D. M., Charlton-Perez, A. J., and Gray, L.J.: Characterising the Variability and Extremes of the Stratospheric Polar Vortices Using 2D Moments, J. Atmos. Sci., 68, 1194-1213, 2011.

O'Callaghan, A., Joshi M. M., Stevens, D. P., and Mitchell: The effects of different sudden stratospheric warming types on the ocean, Geophys. Res. Lett., 41, 7739-7745, doi:10.1002/2014GL062179, 2014.

Roeckner, E., Brokopf, R., Esch, M., Giorgetta, M., Hagemann, S., Kornblueh, L., Manzini, E., Schlese, U., and Schulzweida, U.: Sensitivity of Simulated Climate to Horizontal and Vertical Resolution in the ECHAM5 Atmosphere Model, J. Climate, 19, 3771-3791, 2006.
Rosier, S. M. and Shine, K. P.: The effect of two decades of ozone change on stratospheric temperature as indicated by a general circulation model, Geophys. Res. Lett., 27, 2617-2620, 2000.

Russell III, J. M., Gordley, L. L., Park, J. H., Drayson, S. R., Hesketh, W. D., Cicerone, R. J., Tuck, A. F., Frederick, J. E., Harries, J. E., and Crutzen, P. J.: The Halogen Occultation Experiment, J. Geophys. Res., 98, 10777-10798, 1993.

Sinha, B., Hirschi, J., Bonham, S., Brand, M., Josey, S. A., Smith, R., and Marotzke, J.: Mountain ranges favour vigorous Atlantic Thermohaline Circulation, Geophys. Res. Lett., 39, L02705, doi:10.1029/2011GL050485, 2012.

Slingo, J. M.: The development and verification of a cloud prediction scheme for the ECMWF model, Q. J. Roy. Meteor. Soc., 113, 899-927, 1987.

Stringer M.: available at: http://www.met.reading.ac.uk/ lem/ large_models/igcm/parallel/ (last access: 21 April 2015), 2012.

Taylor, C. P. and Bourqui, M. B.: A new fast stratospheric ozone chemistry scheme in an intermediate general-circulation model. I: Description and evaluation, Q. J. Roy. Meteor. Soc., 131, 2225-2242, 2005.

Thorncroft, C. D., Hoskins, B. J., and McIntyre, M. E.: Two paradigms of baroclinic lifecycle behaviour, Q. J. Roy. Meteor. Soc., 119, 17-55, 1993.

Uppala, S. M., Kållberg, P. W., Simmons, A. J., Andrae, U., da Costa Bechtold, V., Fiorino, M., Gibson, J. K., Haseler, J., Hernandez, A., Kelly, G. A., Li, X., Onogi, K., Saarinen, S., Sokka, N., Allan, R. P., Andersson, E., Arpe, K., Balmaseda, M. A., Beljaars, A. C. M., van de Berg, L., Bidlot, J., Bormann, N., Caires, S., Chevallier, F., Dethof, A., Dragosavac, M., Fisher, M., Fuentes, M., Hagemann, S., Hólm, E., Hoskins, B. J., Isaksen, L., Janssen, P. A. E. M., Jenne, R., McNally, A. P., Mahfouf, J.-F., Morcrette, J.-J., Rayner, N. A., Saunders, R. W., Simon, P., Sterl, A., Trenberth, K. E., Untch, A., Vasiljevic, D., Viterbo, P., and Woollen, J.: The ERA-40 re-analysis, Q. J. Roy. Meteor. Soc., 131, 2961-3012, 2005.

Valdes, P. J. and Hoskins, B. J.: Nonlinear Orographically Forced Planetary Waves, J. Atmos. Sci., 48, 2089-2106, 1991.

Winter B. and Bourqui, M. S.: The Impact of Surface Temperature Variability on the Climate Change Response in the Northern Hemisphere Polar Vortex, Geophys. Res. Lett., 38, L08808, doi:10.1029/2011GL047011, 2011a.

Winter B. and Bourqui, M. S.: Sensitivity of the Stratospheric Circulation to the Latitude of Thermal Surface Forcing, J. Climate, 24, 5397-5415, 2011b.

Xie, P. and Arkin, P. A.: Global precipitation: a 17-year monthly analysis based on gauge observations, satellite estimates, and numerical model outputs, B. Am. Meteorol. Soc., 78, 2539-2558, 1997.

Zhai, X., Johnson, H. L., and Marshall, D. P.: A simple model of the response of the Atlantic to the North Atlantic Oscillation, J. Climate, 27, 4052-4069, doi:10.1175/JCLI-D-13-00330.1, 2014.

Zhong, W. Y. and Haigh, J. D.: Improved broad-band emissivity parameterization for water vapor cooling calculations, J. Atmos. Sci., 52, 124-138, 1995. 